\title{
Regulation of Gene Expression in Neural Stem Cell Differentiation and Self-Renewal
}

\author{
Mohammad Reza Hashemzadeh ${ }^{1 *}$, Zahra Seyedi², Mohammad Amin Edalatmanesh ${ }^{3}$, Samaneh Rafiei $^{3}$ \\ ${ }^{1}$ Department of Stem Cells and Regenerative Medicine, Royesh Stem Cell Biotechnology Institute, Mashhad, Iran \\ ${ }^{2}$ Department of Cancer and Oncology, Royesh Stem Cell Biotechnology Institute, Mashhad, Iran \\ ${ }^{3}$ Department of Physiology, College of Sciences, Shiraz Branch, Islamic Azad University, Shiraz, Iran
}

\section{A BSTRACT}

Introduction: Stem cells are characterized by two fundamental properties; self-renewal and differentiation. Self-renewal is an integration of proliferation control with the maintenance of an undifferentiated state. Self-renewal trait is regulated by a dynamic process between transcription factors, epigenetic control, microRNA regulators, and cell-extrinsic signals from the niche of stem cells. The other feature of stem cells is the capability of differentiation to various cell types. Neural stem cells are able to differentiate to neuron, glial cell, and oligodendrocyte. The process of oligodendrocyte differentiation also is regulated by an interaction between the genetic and epigenetic programs. Recent studies reveal the key role of histone modifications in epigenetic regulation of gene expression during oligodendrocyte development. Moreover, retinoic acid pathway has been shown in stem cell differentiation toward neurons. Conclusion: Detection of signaling cascades and regulatory networks of self-renewal and differentiation of neural stem cells improve new therapeutic methods for neural diseases, such as brain injuries and brain tumors as well as neurodegenerative diseases, like Huntington, Alzheimer, Parkinson, and demyelination diseases, such as multiple sclerosis. Moreover, understanding of these pathways leads to specific and stable differentiation of neural stem cells toward functional oligodendrocyte for alternative therapy.

\section{Key words:}

1. Cell Differentiation

2. Gene Expression

3. Neural Stem Cells

4. Cell Self Renewal

* Corresponding Author: Mohammad Reza Hashemzadeh

E-mail: hashemzadeh@royesh-scb.com 
تنظيم بيان زن در تمايز و خودنوزايى سلولهاى بنيادى عصبى
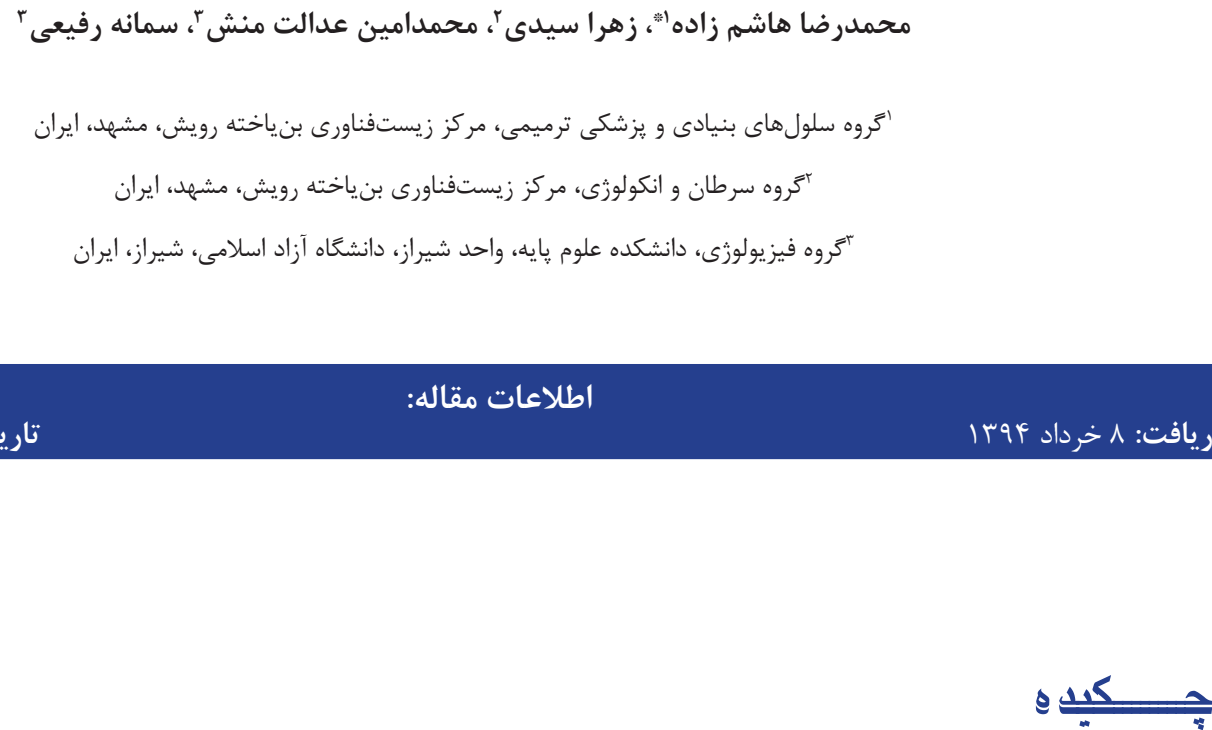

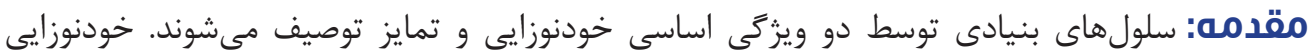

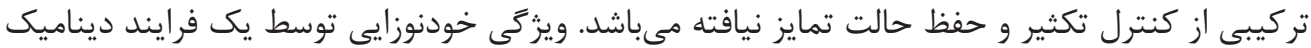

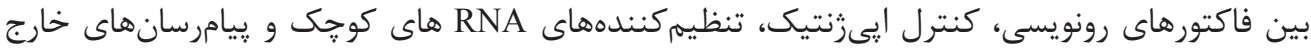

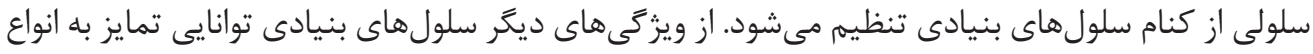

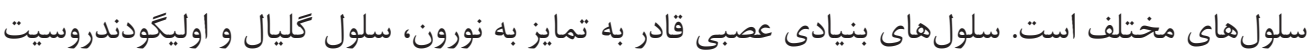

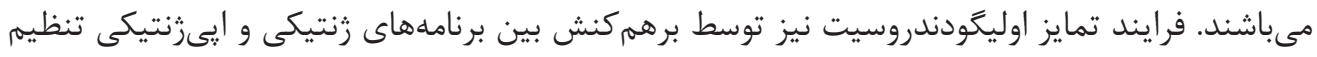

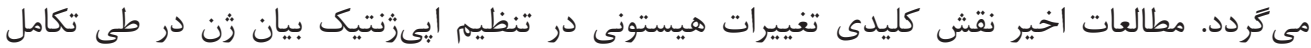

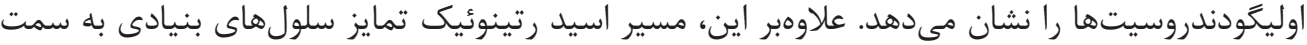

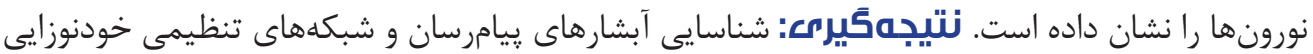

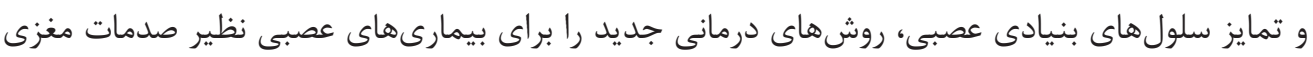

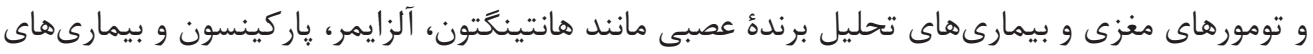

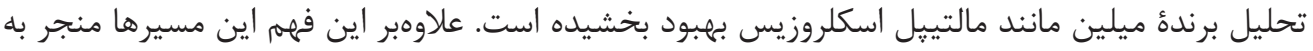

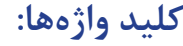

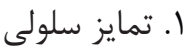

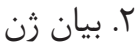

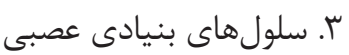

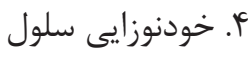

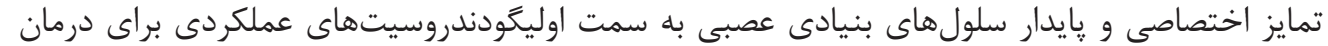
جايكزين مى تردد. 


\section{تنظيم كنندهاى رونويسى}

كيرنده هستهاى TLX يك تنظيمكنـده ضرورى در حفظ

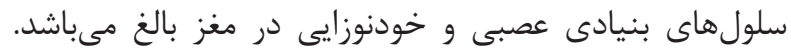

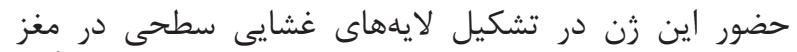

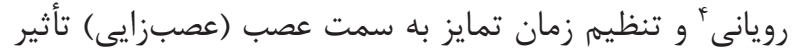

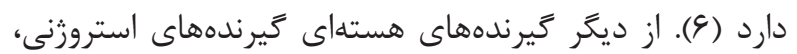

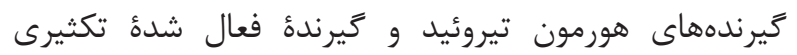

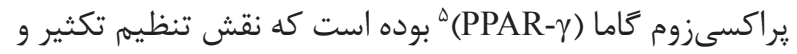

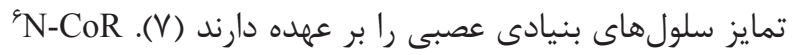

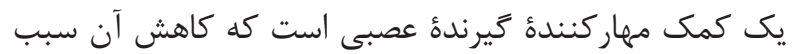

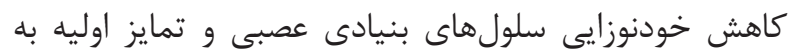

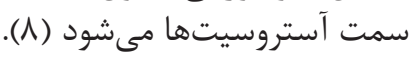

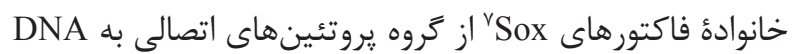
با حركت بالا هستند كه در حفظ حالت الت تمايزنيافتكى سلول هاى بنيادى عصبى نقش دارند. در مهرهداران فاكتورهاى SoxB1

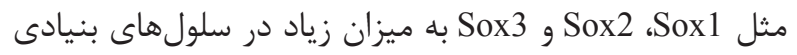

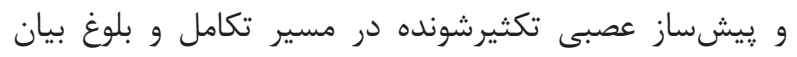

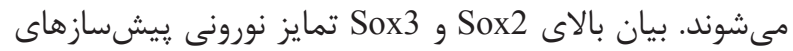

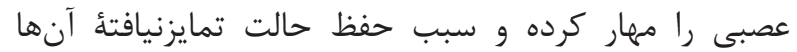

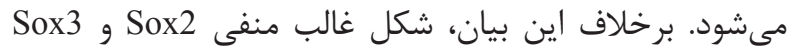

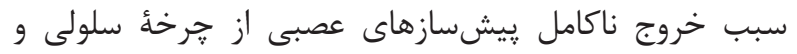

شروع تمايز عصبى ميى شود (9).

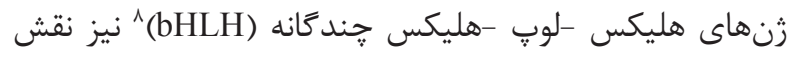
مهمى در تنظيم حفظ سلولهاء هن بنيادى عصبى و تمايزشان

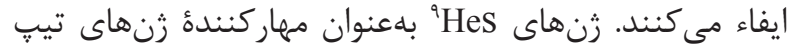

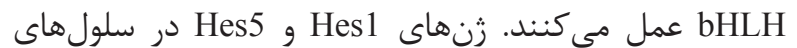

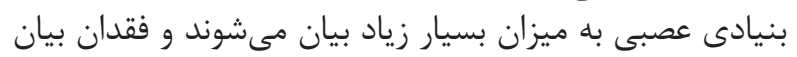

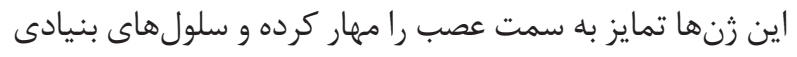

\section{مقدمه - مق}

سلولهاى بنيادى، سلولهاى تمايزنيافتهاى هستند كه داراى دو

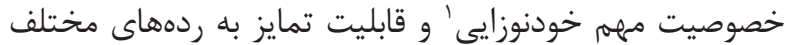

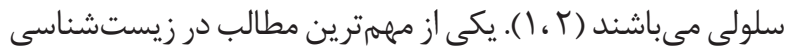

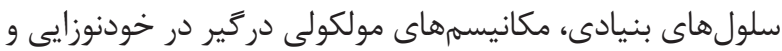

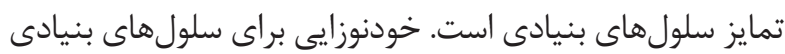

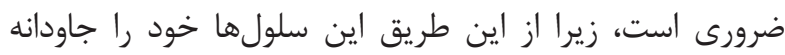

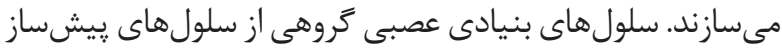

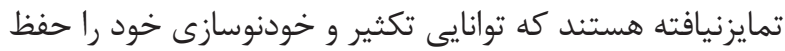

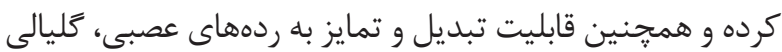

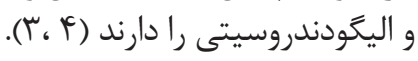

روند تكامل متشكل از رشد، تمايز و ريختزايى مىباشد كه در هر

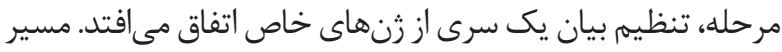

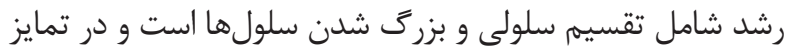

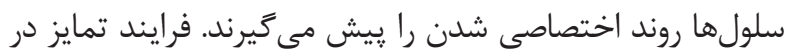

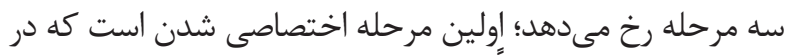

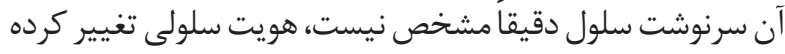

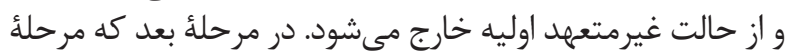

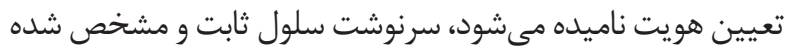

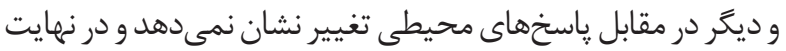

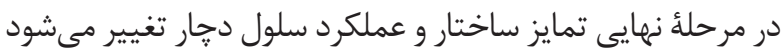

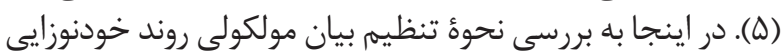

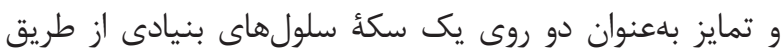
مكانيسمهاى درون و برون سلولى مى بهيردازيم.

$$
\text { مكانيسمهاى تنظيمى درون سلولى }
$$

اين مكانيسمها رامى توان در هُند بخش از جمله تنظيم كننده هاى

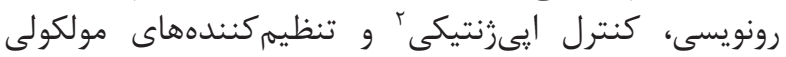
RNA

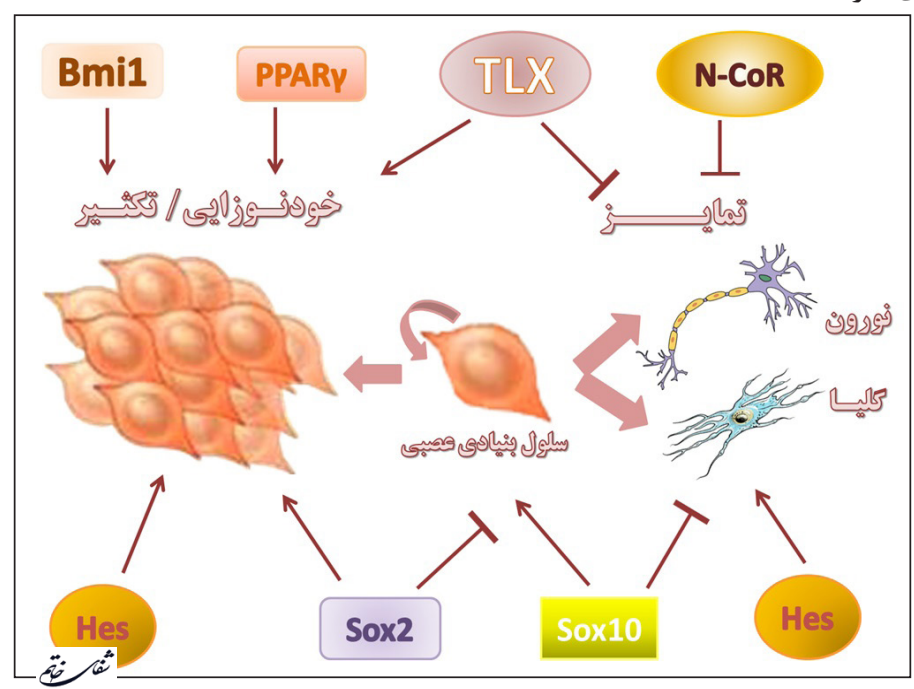

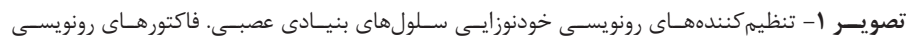

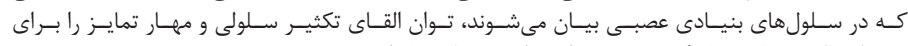

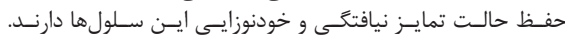

${ }^{1}$ Self-renewal

${ }^{2}$ Epigenetic

${ }^{3}$ Nuclear receptor TLX

${ }^{4}$ Embryonic brain

${ }_{5}^{5}$ Peroxisome proliferator-activated receptor gamma
${ }^{6}$ Nuclear receptor co-repressor

${ }^{7}$ Sarbanes-oxley factors

${ }^{8}$ Basic helix-loop-helix

${ }^{9}$ Hairy and enhancer of split 
مىباشد. در سلولهاى غيرعصبى، REST با كوفاكتورهاى خود

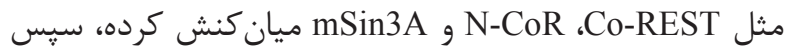

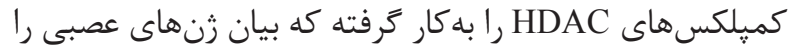

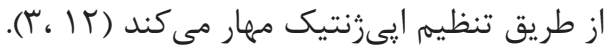

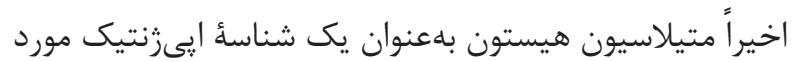

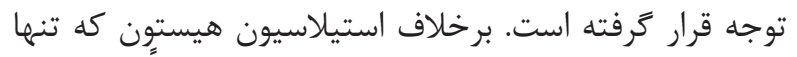

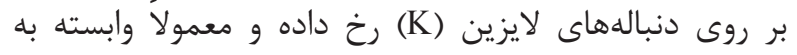

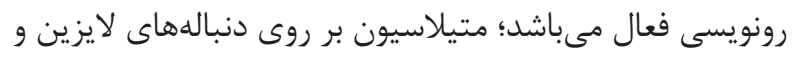

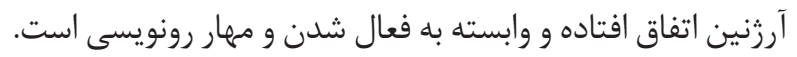

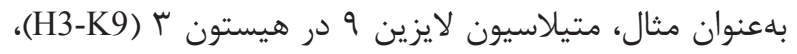

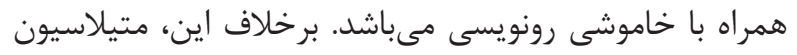

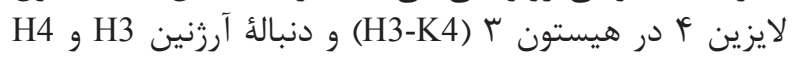

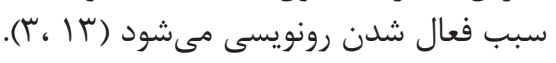

درجهُ متيلاسيون لايزين (مونو، دى، يا ترى متيل هيستونها)

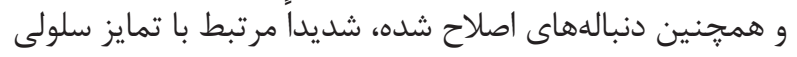

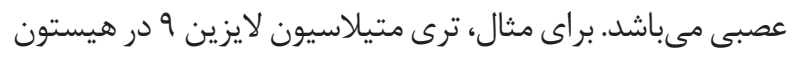

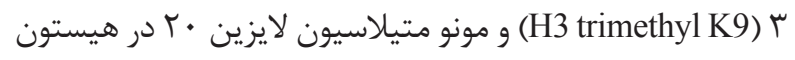

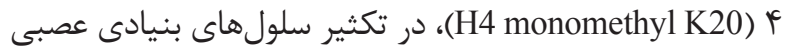

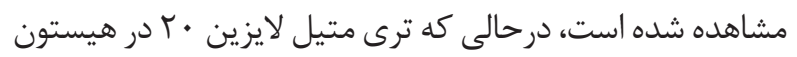

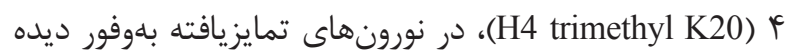

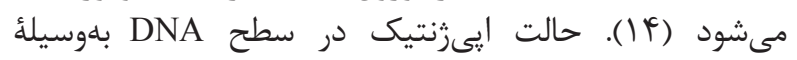
متيلاسيون DNA تنظيم مى مئود. برجستهترين شكل متيلاسيون

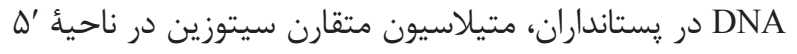

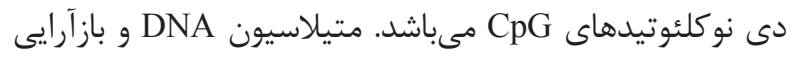

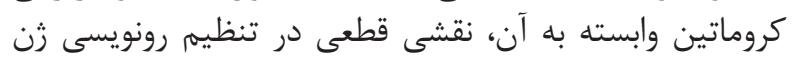

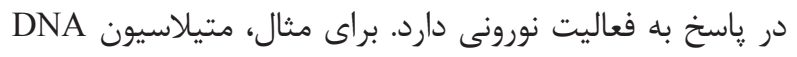

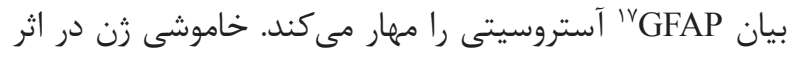

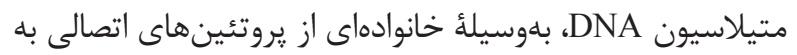

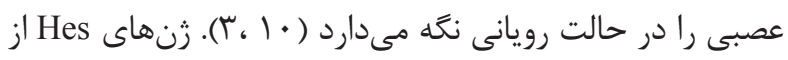

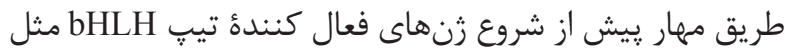
Mash1، Math عصبى را تنظيم مى كنند (تصوير ()).

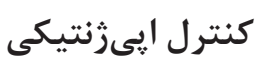

خودنوزايى و تمايز سلولهاى بنيادى نتيجة كنترل فرايند

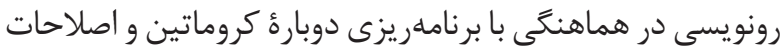

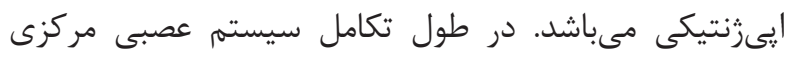

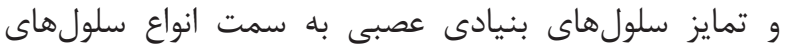

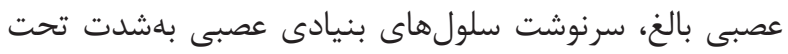

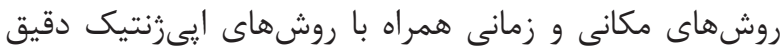

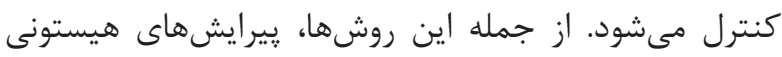
كوالان و متيلاسيون دى نوكلئوتيدهاى

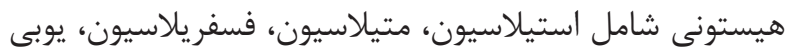

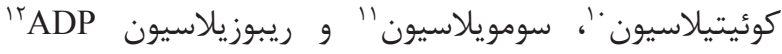

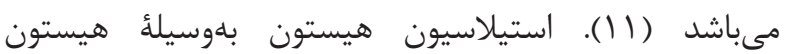

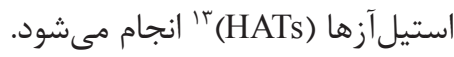

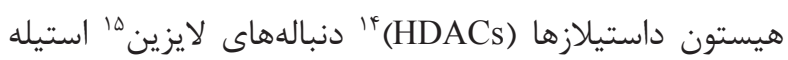

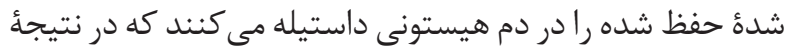

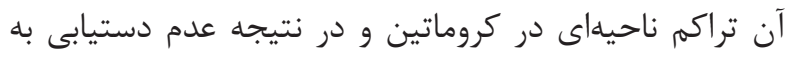

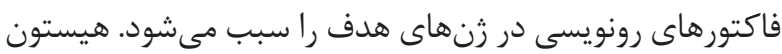

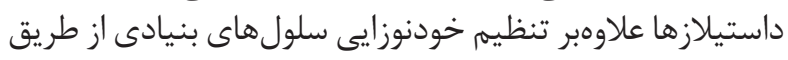

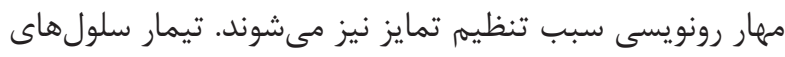

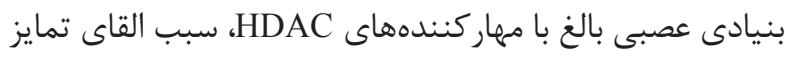

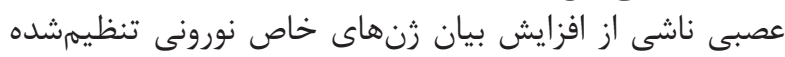
توسط REST'

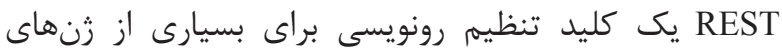

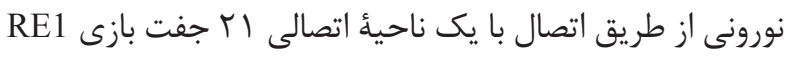

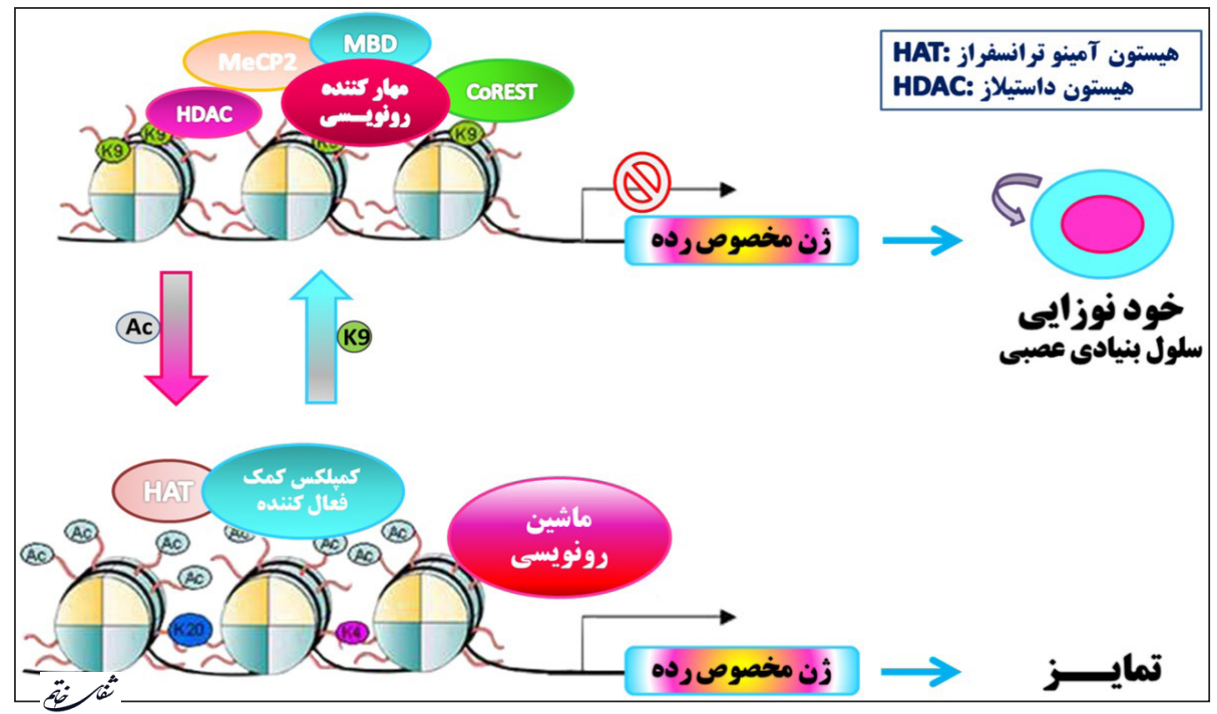

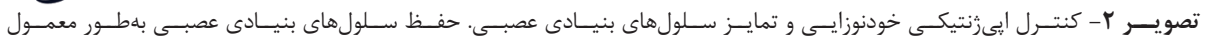

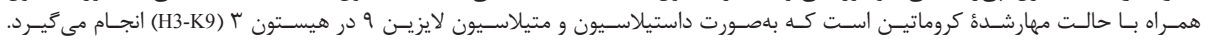

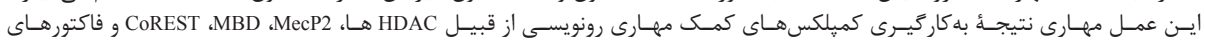

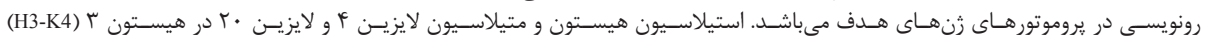

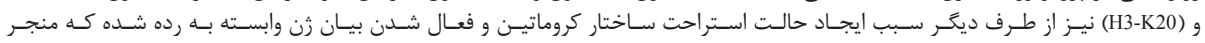

${ }^{10}$ Ubiquitylation

${ }^{11}$ Sumoylation

${ }^{12}$ ADP-ribosylation

${ }^{13}$ Histone acetyltransferases

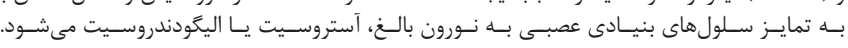

${ }^{14}$ Histone deacetylases

${ }^{15}$ Lysine

${ }^{16}$ RE1-Silencing Transcription factor

${ }^{17}$ Glial fibrillary acidic protein 
miRNA

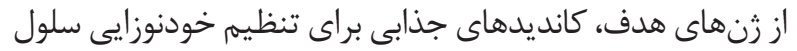

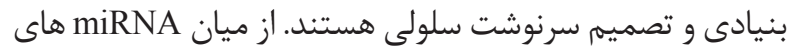

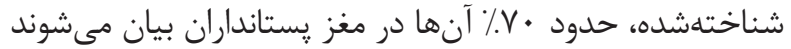

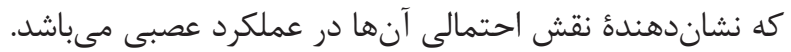

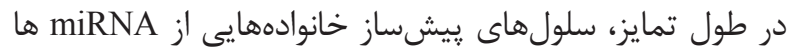

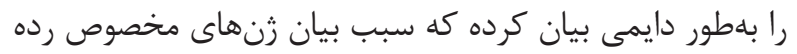

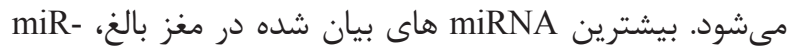

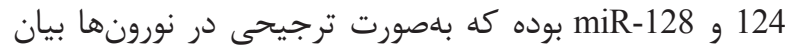
مىشود، درحالى كه miR-23 محدود به تمايز آستروسيتى و و

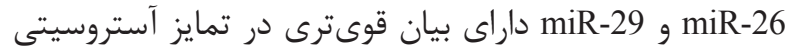
نسبت به تمايز نورونى هستند. دو نوع miR-9 و و

تمايز هر دو گروه بهطور يكسان بيان مي نورني همند (IV). بيان بالاى miR-128، miR-124 و miR-9 در ريشسازهاى عصبى، تمايز آستروسيتها را كاهش ميىدهد. برخلاف اين،

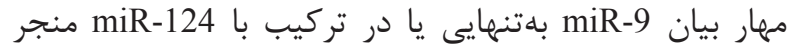

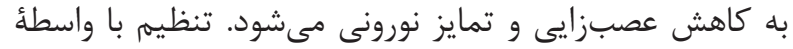

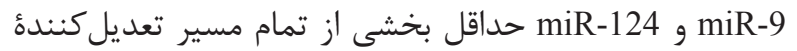

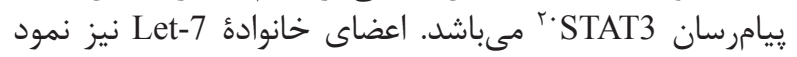

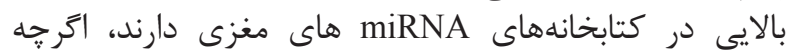

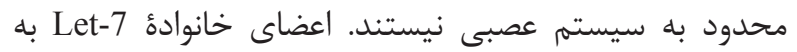

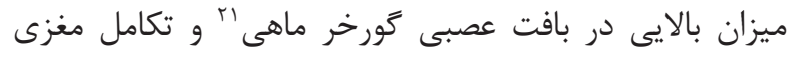

متيل -سيتوزين مثل MeCP2^ كه بلهوفور در سيستم عصبى داسي

مركزى ديده شده است، ايجاد مى شود (ه (1).

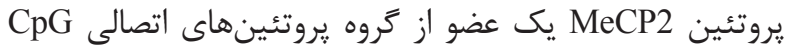

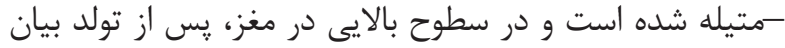

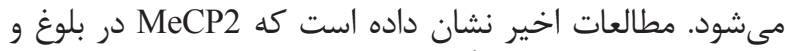

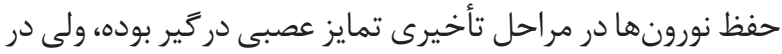

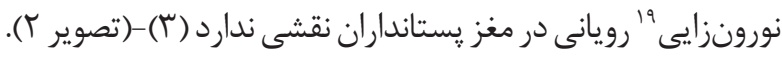

\section{miRNA تنظيم:كنندههاى}

بسيارى از كلاسهاى متفاوت RNA هاى غيركدشونده در مغز

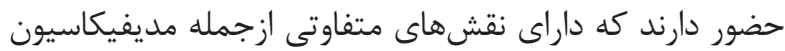

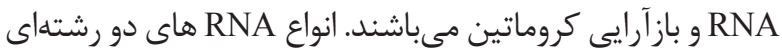

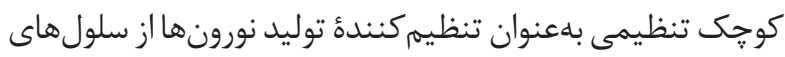

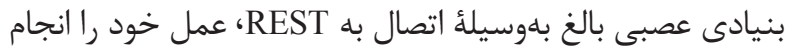

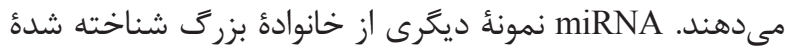

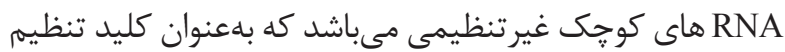

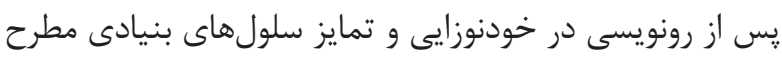

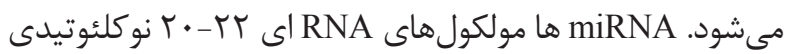

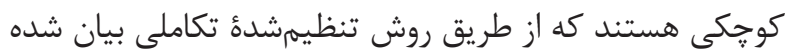

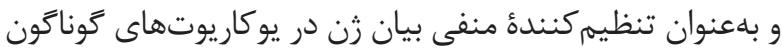

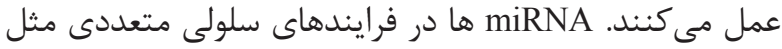
تكامل، تكثير و تمايز درگير مى مباشند (ع) (1).

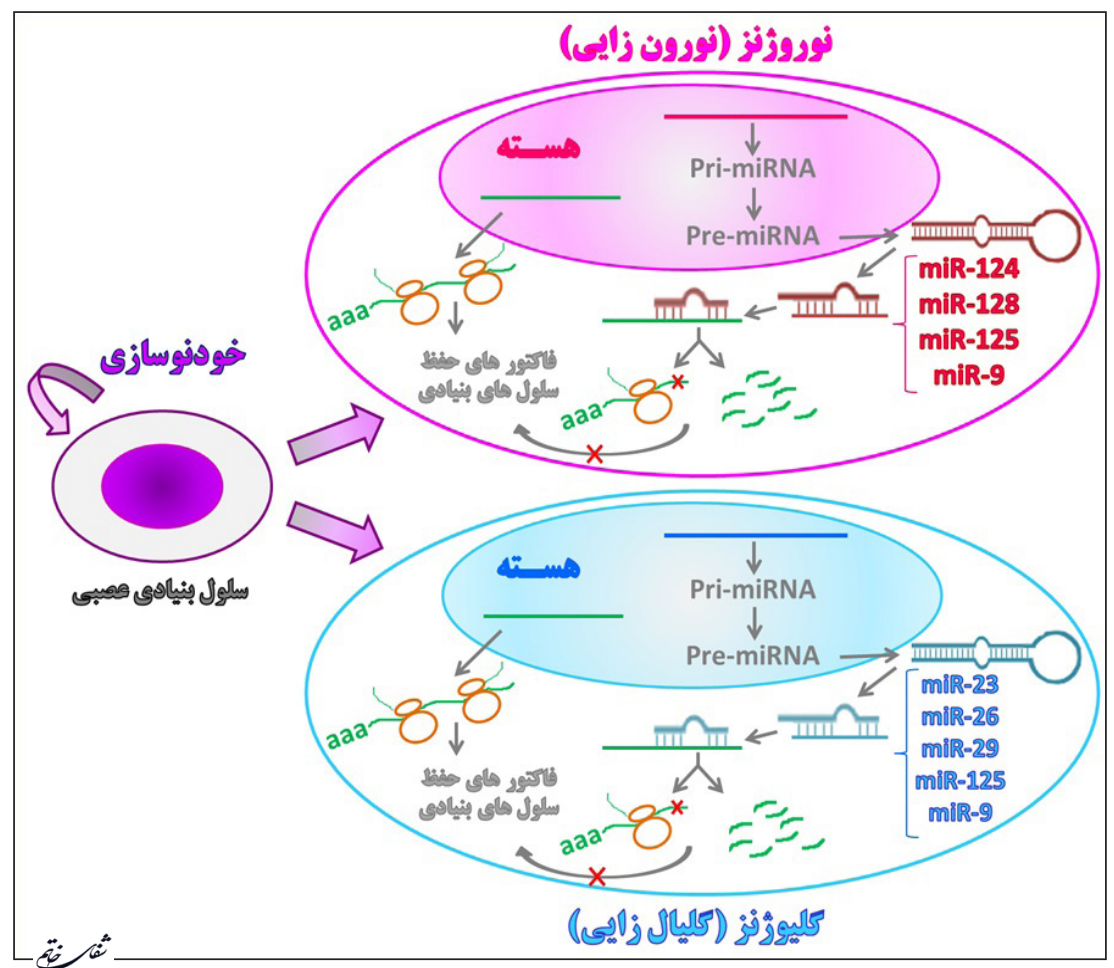

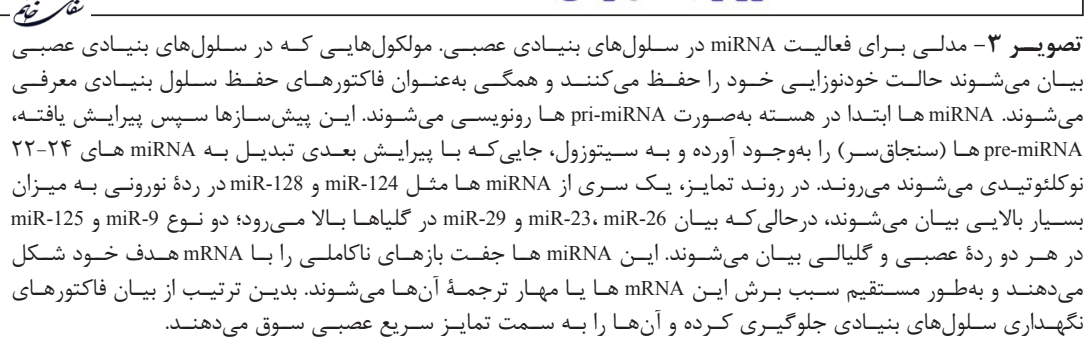

${ }^{18}$ Methyl CpG binding protein 2

${ }^{19}$ Neurogenesis
${ }^{20}$ Signal transducer and activator of transcription 3
${ }^{21}$ Zebrafish 


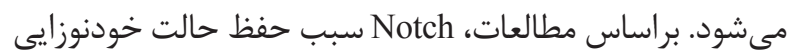
و همجنين القاى نهايى تمايز كليالى مىشود (· (T). فاكتور رشد إيدرمى (EGF)

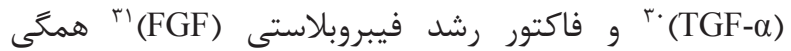

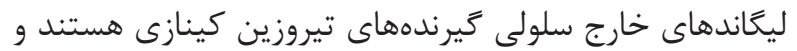

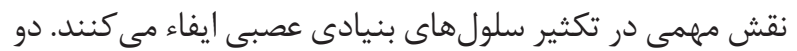

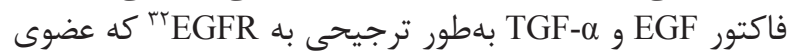

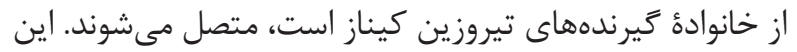

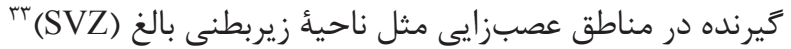

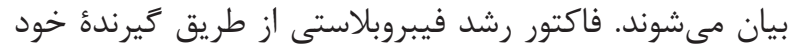

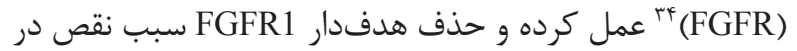

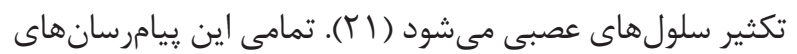

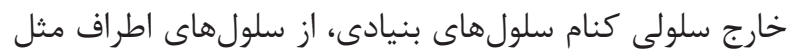

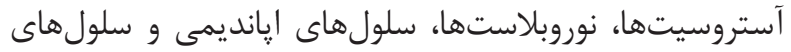

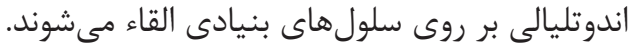

مسير بيامرسانى اسيد رتينوئيك بهعنوان مورفوثن در

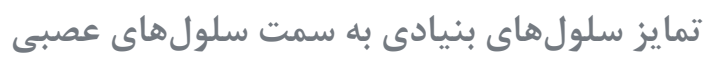

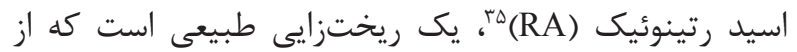

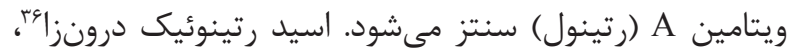

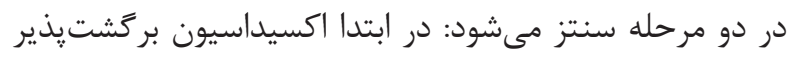

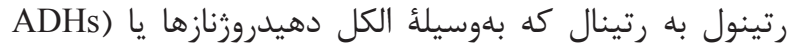
RDHs/ SDRs

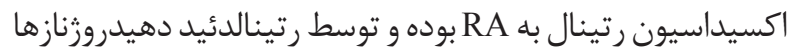
(RALDHs)

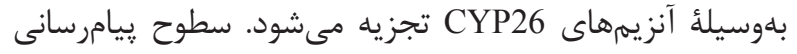

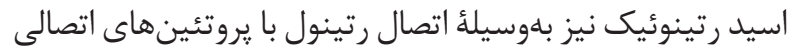

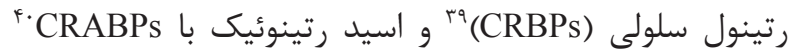
صورت مى كيرد (Tr)-(تصوير F (-الف).

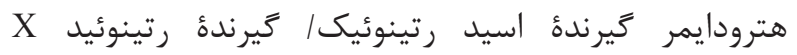
(RAR/RXR)

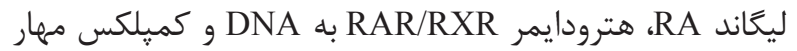

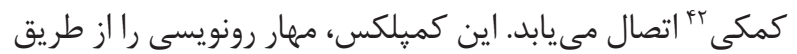

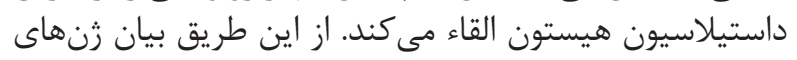

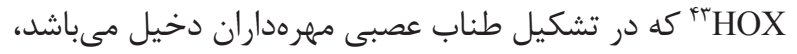

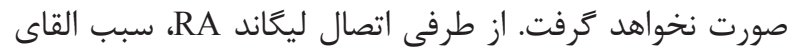

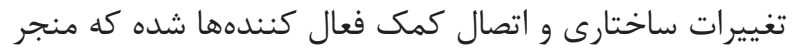

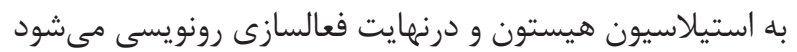

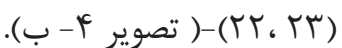

\footnotetext{
${ }^{22}$ Signaling

${ }^{23}$ Sonichedgehog

${ }^{24}$ Receptor tyrosine kinase

${ }^{25}$ Beta-catenin

${ }^{26}$ Delta

${ }^{27}$ Proteolytic

${ }^{28}$ Campus service learning

${ }^{29}$ Epidermal growth factor

${ }^{30}$ Transforming growth factor alpha

${ }^{31}$ Fibroblast growth factor

${ }^{32}$ Epidermal growth factor receptor

${ }^{33}$ Subventricular zone
}

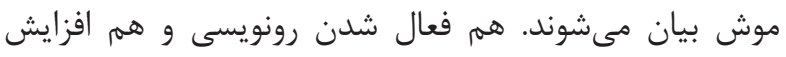

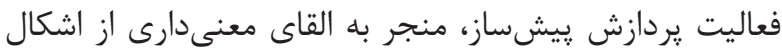

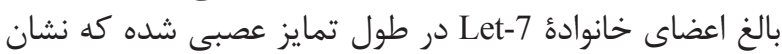

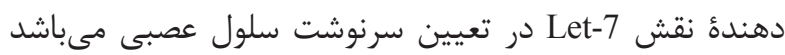

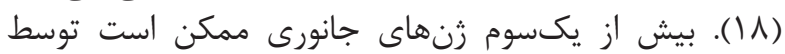

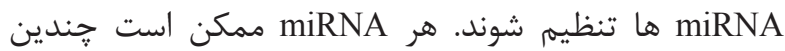

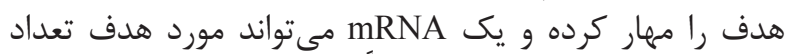

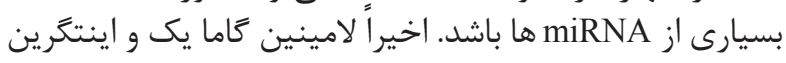

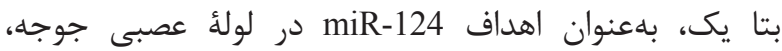

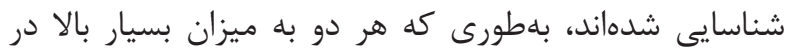

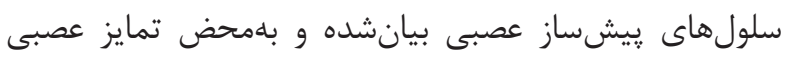
مهار مىشوند. علاوهبر اين،

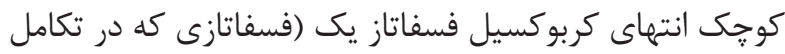

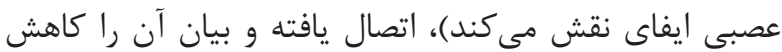

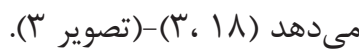
بيامرسانى خارج سلولى خودنوزايى و تمايز سلولهاى بنيادى توسط محيط اطراف اين

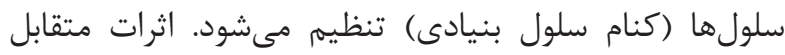

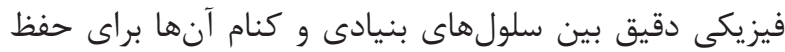

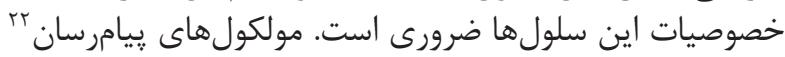

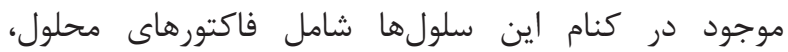

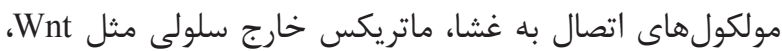

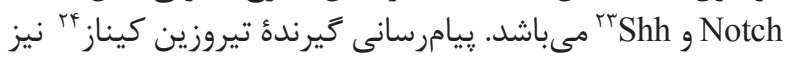

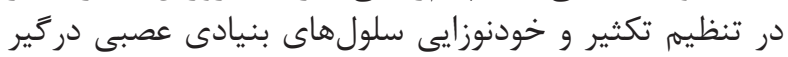

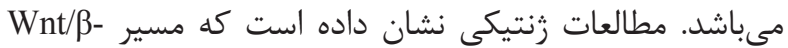
catenin

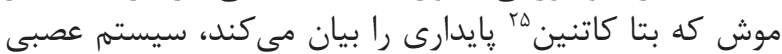

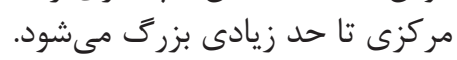

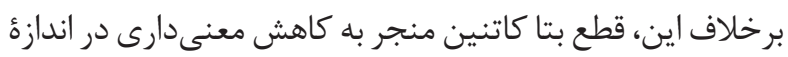

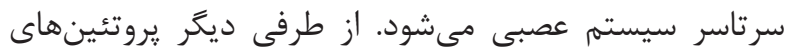

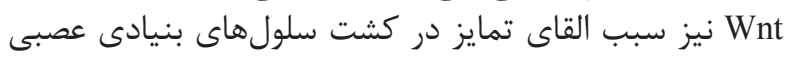

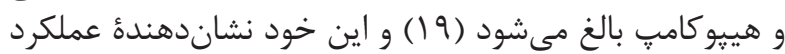

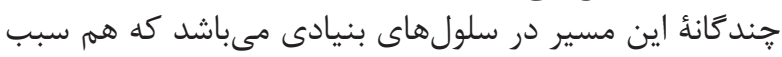

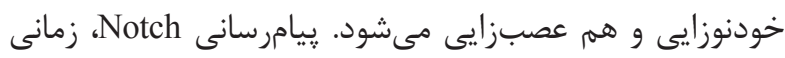

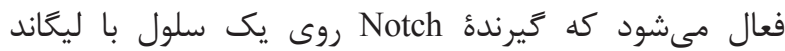

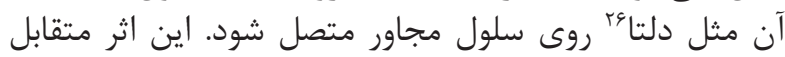

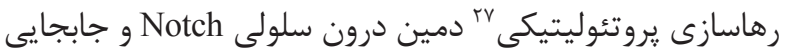

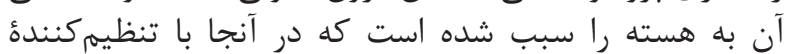

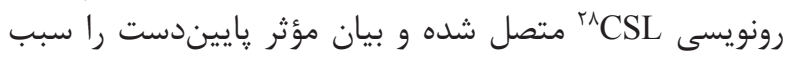

${ }^{34}$ Fibroblast growth factor receptor

${ }^{35}$ Retinoic acid

${ }^{36}$ Endogenous retinoic acid

${ }^{37}$ Alcohol dehydrogenases and retinol dehydrogenases/ shortchain dehydrogenase reductase

${ }^{38}$ Retinaldehyde dehydrogenases

${ }^{39}$ Cellular retinol-binding proteins

${ }^{40}$ Cellular retinoic acid-binding proteins

${ }^{41}$ Retinoic acid receptor and retinoid $\mathrm{X}$ receptor

${ }^{42}$ Co-repressor complex

${ }^{43}$ Homeobox gene 


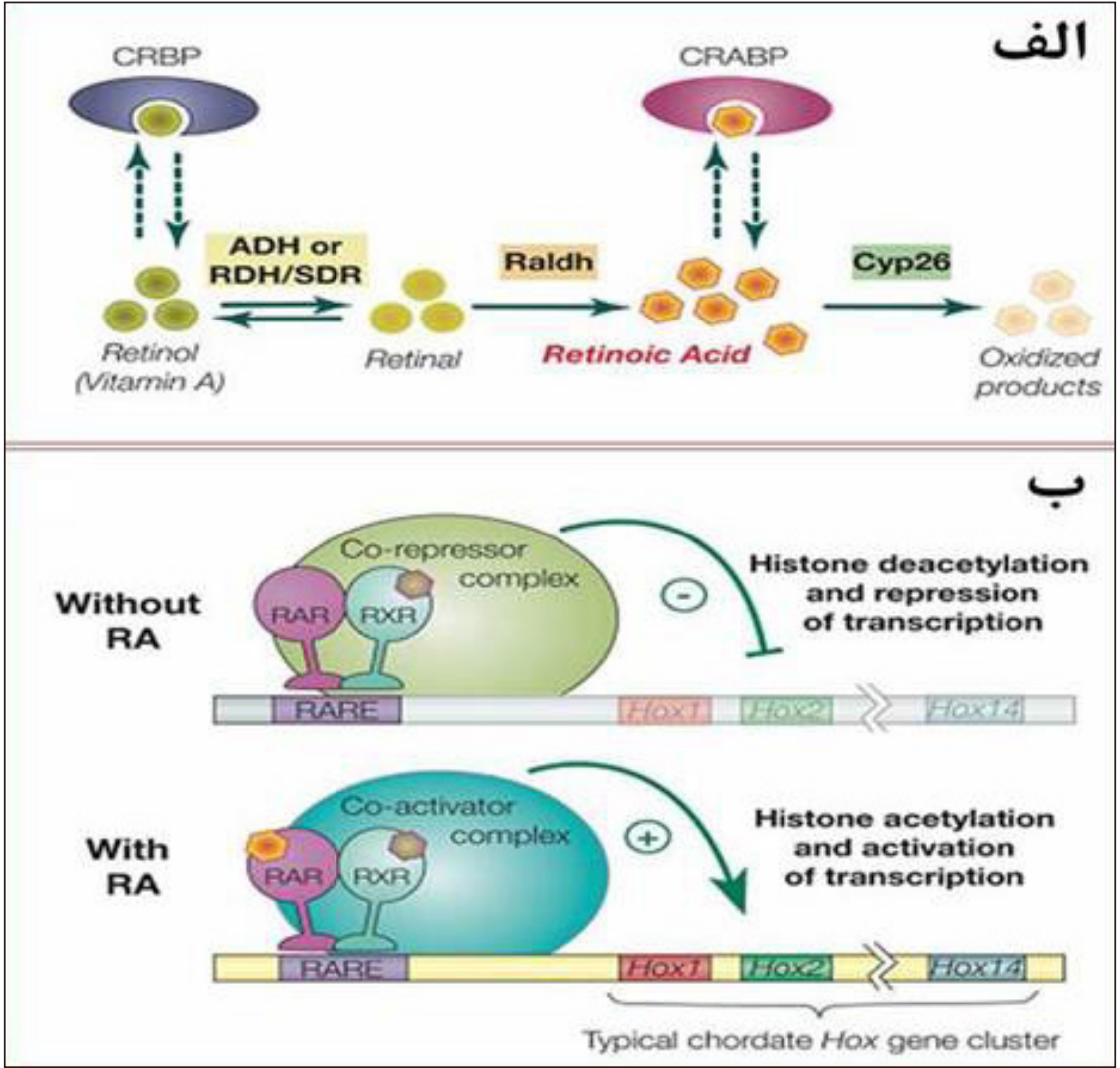

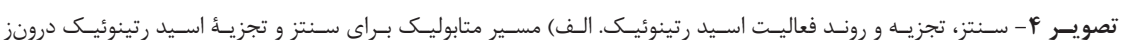

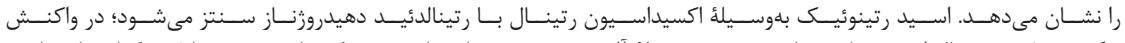

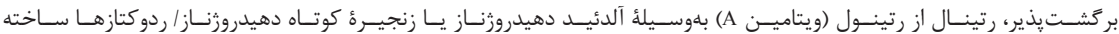

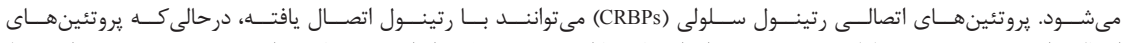

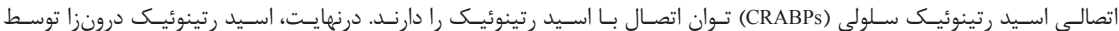

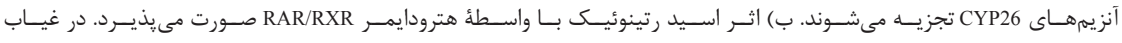

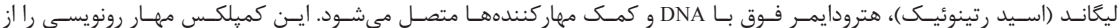

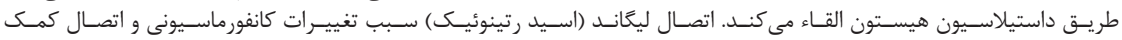

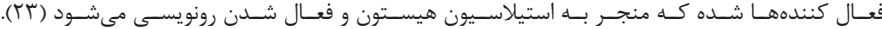

هيستون استيل ترانسفرازها (HATs) و تمايز سلولهاى بنيادى عصبى به اليخودندروسيتها سرعت و شكل تغييرات هيستونى در اليغودندروسيتها

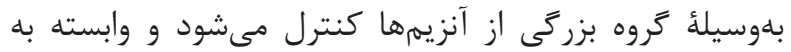

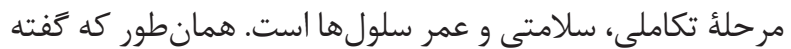

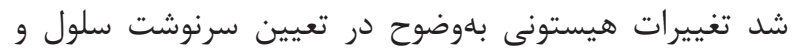

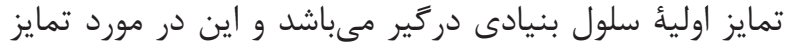

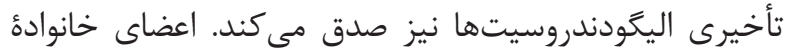

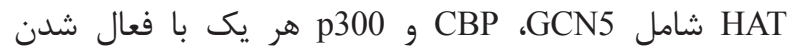

$$
\text { رونويسى همراه مىشوند (YY). }
$$

هيستون استيلازها، نقش مهرى را در تمايز سلولهاى بنيادى عصبى نشان دادهاند. در حقيقت،

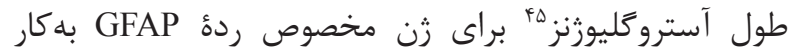

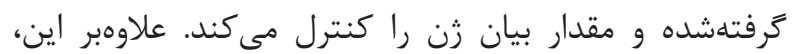

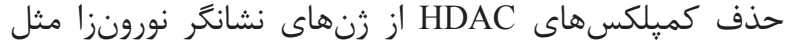
Neuro D
تنظيم بيان زن در تمايز سلولهاى بنيادى عصبى به

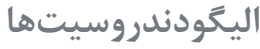

فرايند تمايز اليكودندروسيتها بهوسيلأ يك تقابل ديناميك بين

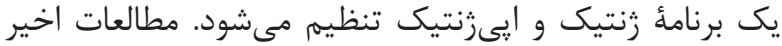

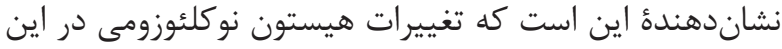

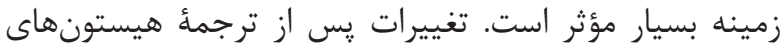

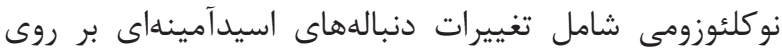
دمهاى هيستونى مىباشد كه اين تغييرات بيان زئن رن، مستقل

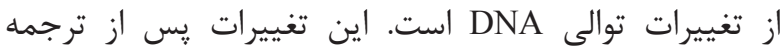

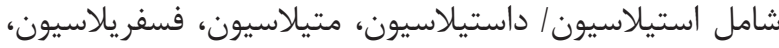

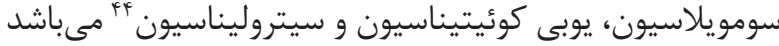

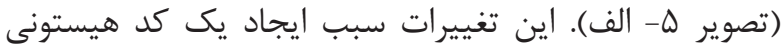

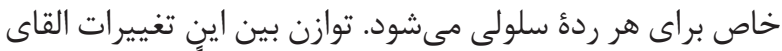

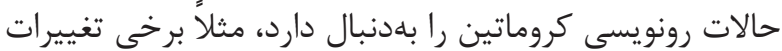

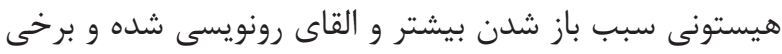

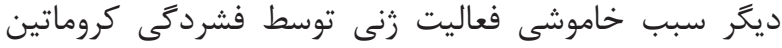
مىشود (تصوير ه-ب و ج).

${ }^{44}$ Citrullination

${ }^{45}$ Astrogliogenesis 


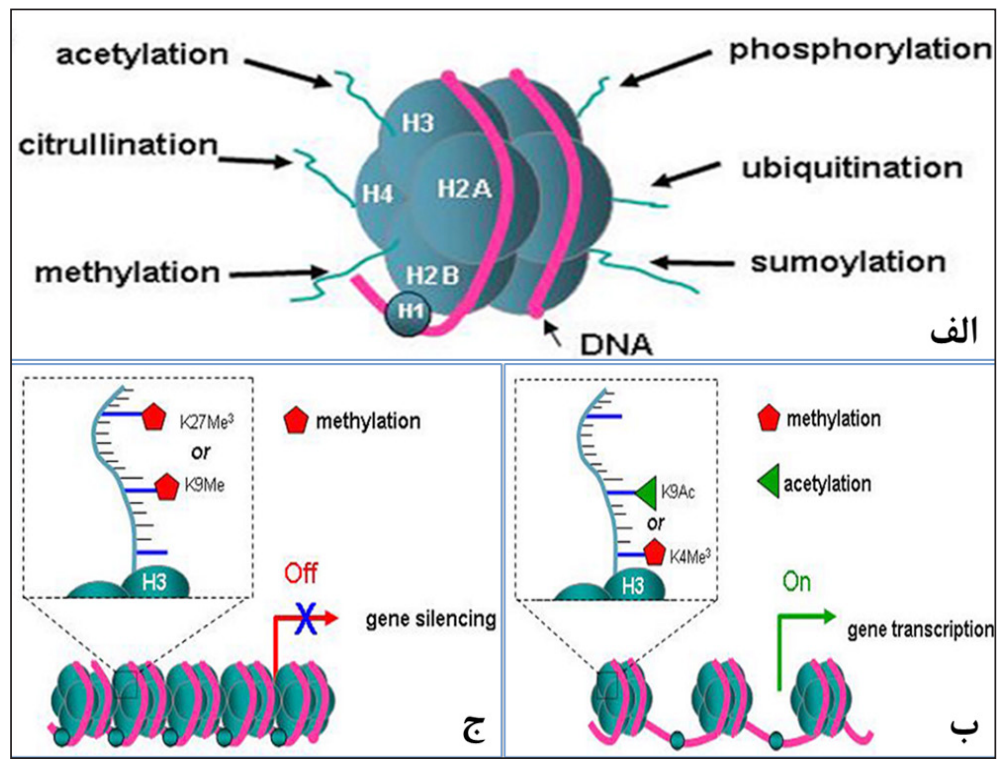

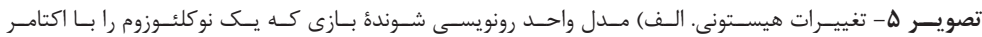

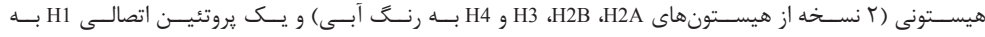

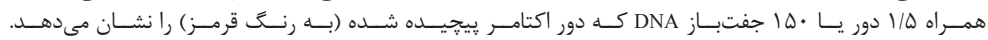

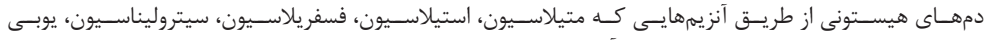

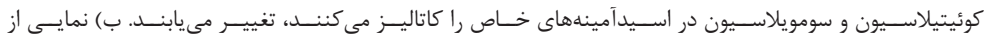

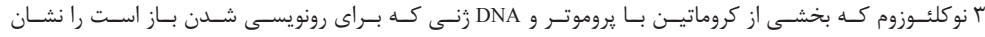

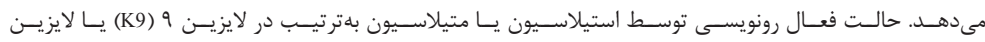

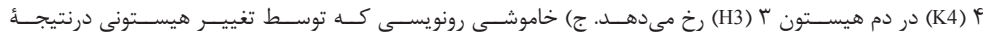

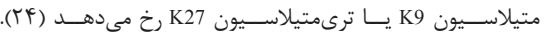

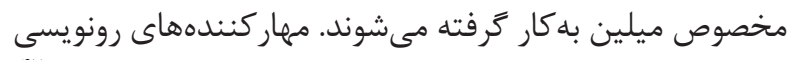

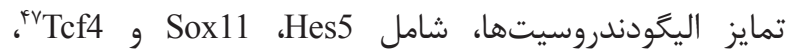

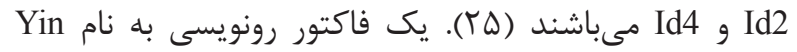

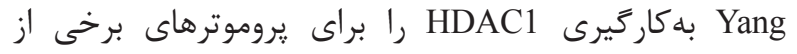

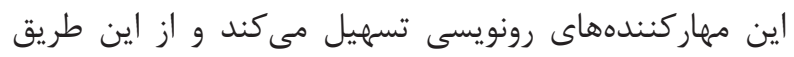

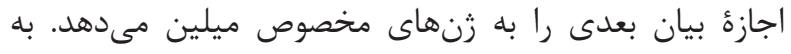

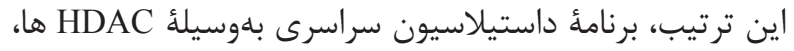

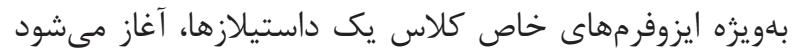

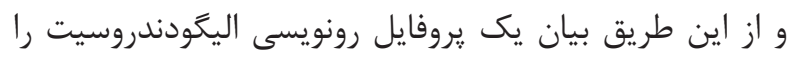

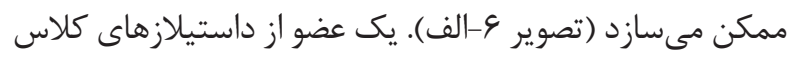

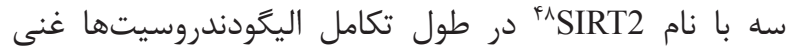

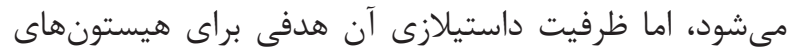

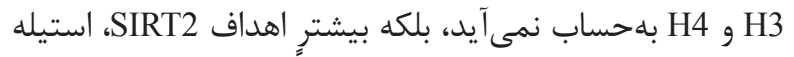

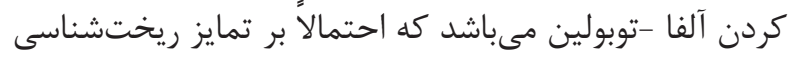

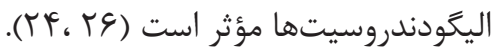

$$
\begin{aligned}
& \text { هيستون متيلترانسفرازها و تمايز سلولهاى بنيادى } \\
& \text { عصبى به اليخودندروسيتها }
\end{aligned}
$$

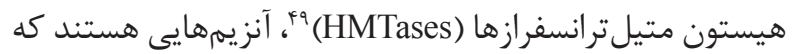

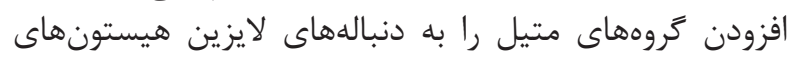

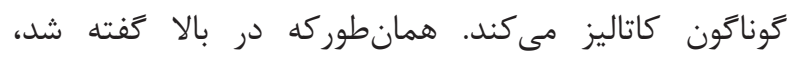

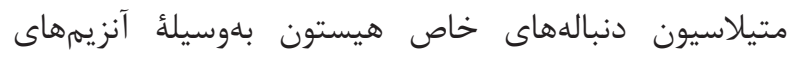

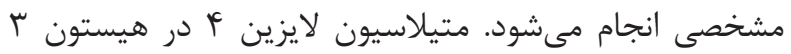

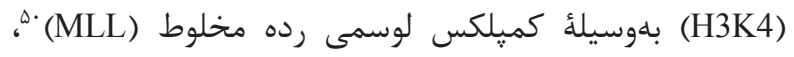

${ }^{46}$ Promoters

${ }^{47}$ Transcription factor 4

${ }^{48}$ Sirtuin-2
استيلاسيون هيستونها براى فعال سازى روند رونويسى جندين رده عصبى ضرورى است، نقش

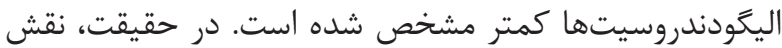

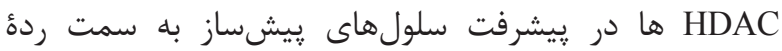
اليكودندروسيت شاخصتر بوده است (YY)-(تصوير \&- الف).

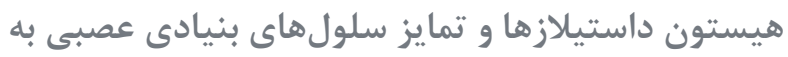

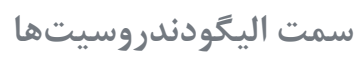
برخلاف ديخر ر رههاى عصبى، تمايز اليكودندروسيتها

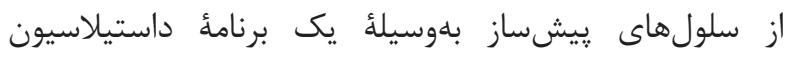

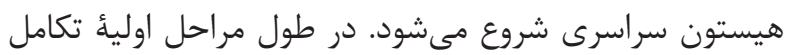

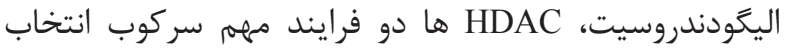

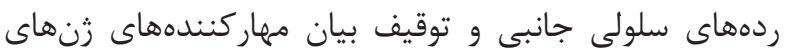

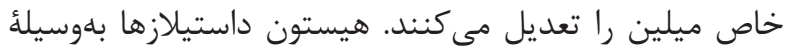

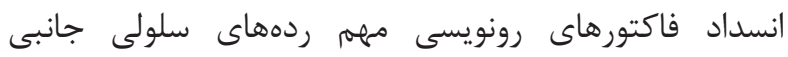

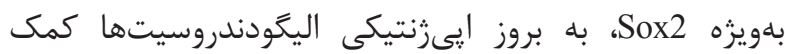

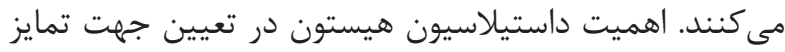

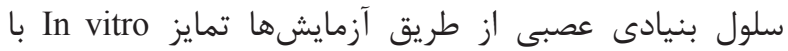

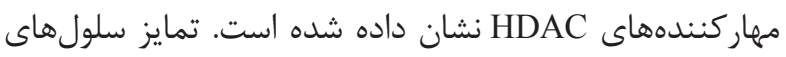

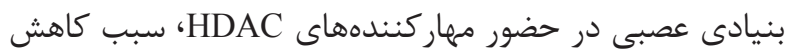

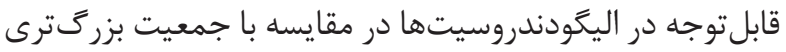

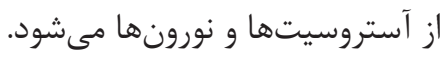

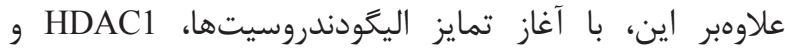

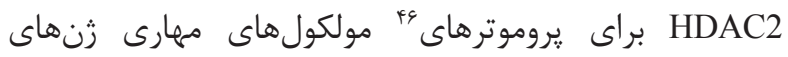

${ }^{49}$ Histone methyltransferases

${ }^{50}$ Mixed-lineage leukemia 
مرحلئ ميلينه شدن اولئُ اليگودندروسيت نابالغ در حد بالا

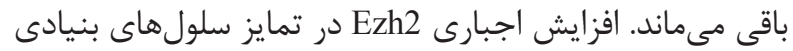

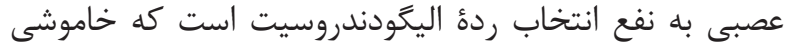

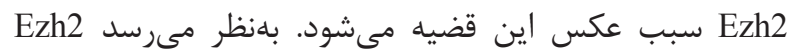
تشكيل OPC را از طريق ريشخيرى انتخاب سرنوشت سلولى فئى

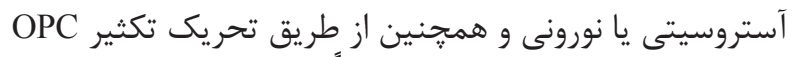

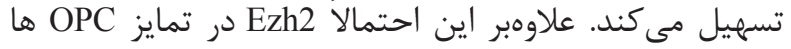

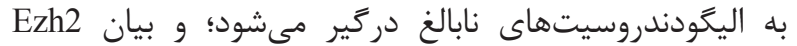

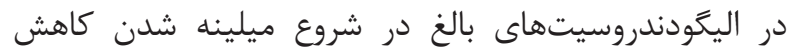

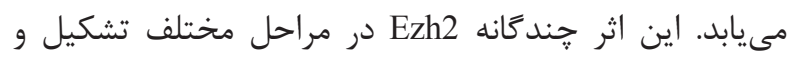

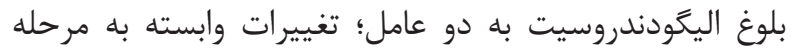

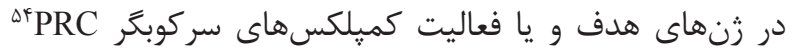

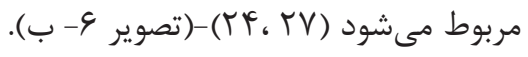

هيستون دمتيلازها و تمايز سلولهاى بنيادى عصبى به

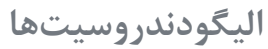

درحالى كه اعتقاد بر اين بود كه متيلاسيون يك تغيير دايمى

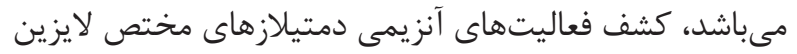

كاتاليز مىشود. مخصوصاً، دمين SET از SLL مسئول

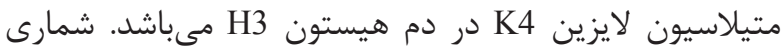
از HMT آزها قادر به متيله كردن هيستون H33

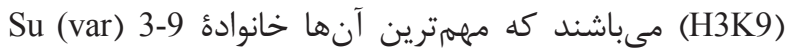

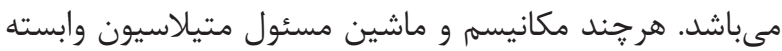

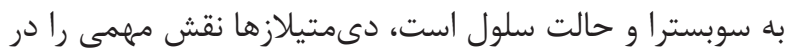

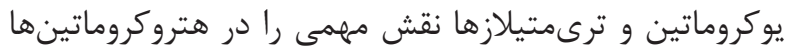

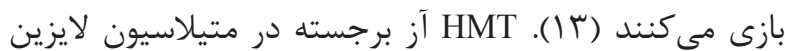

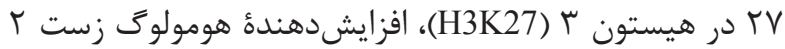

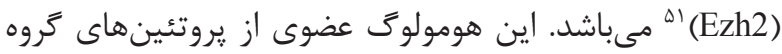

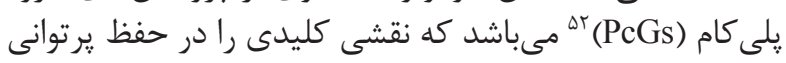

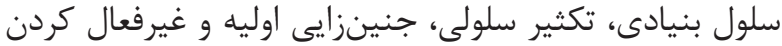
كروموزوم X بازى مى كند.

مشخص شده است كه متيلاسيون H3K27 توسط Ezh2 در

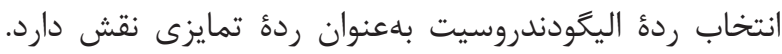

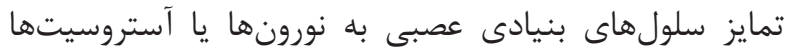

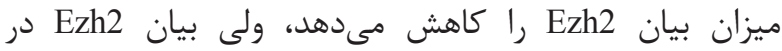

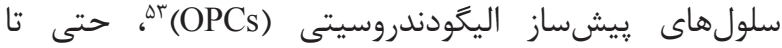

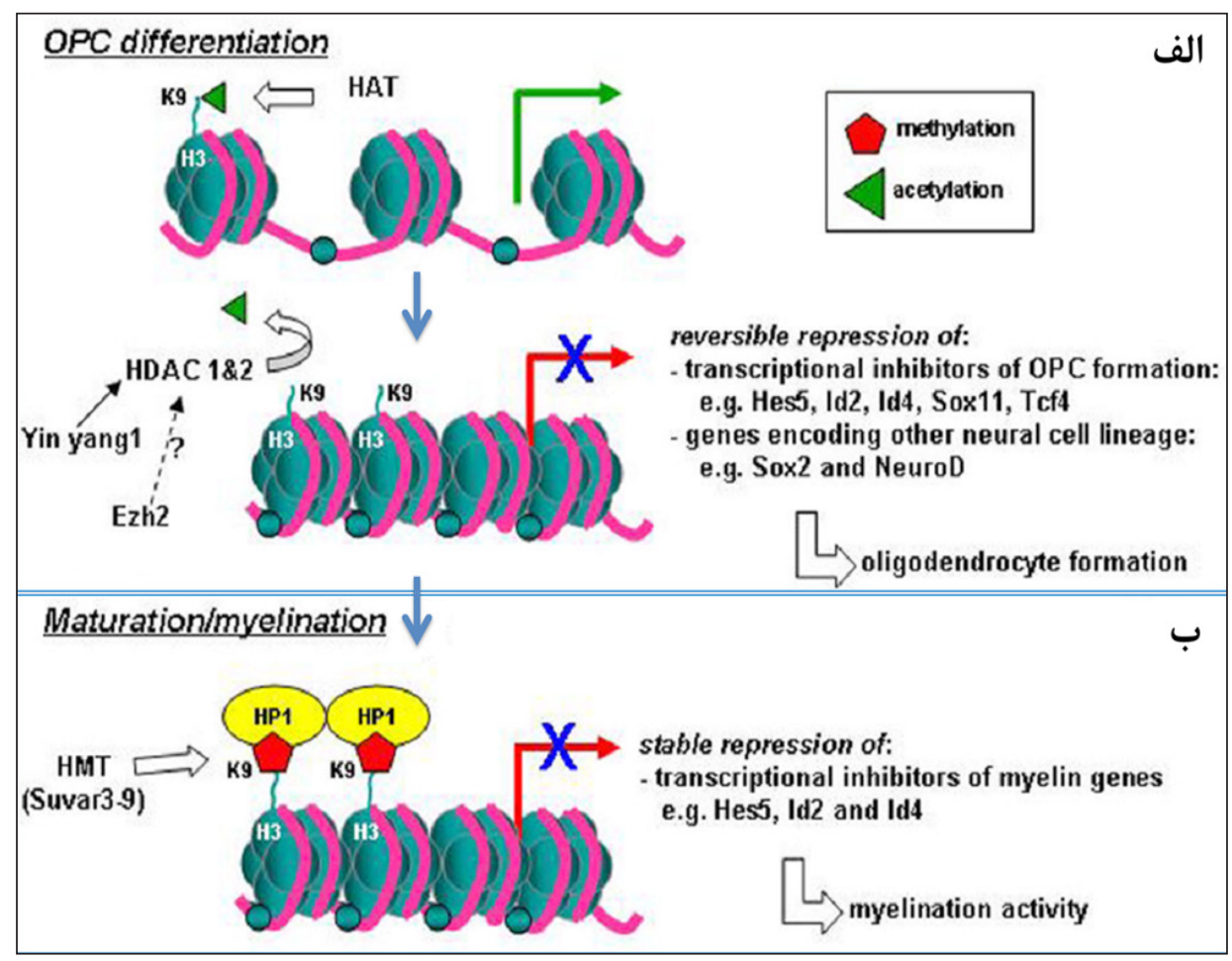

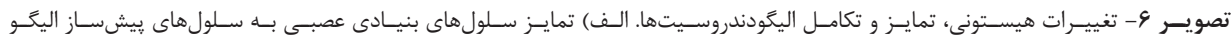

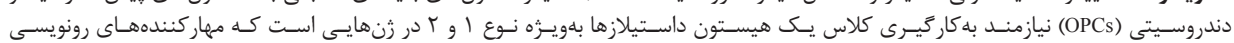

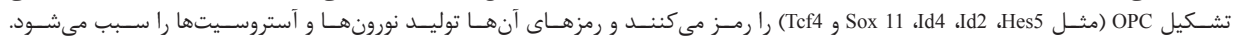

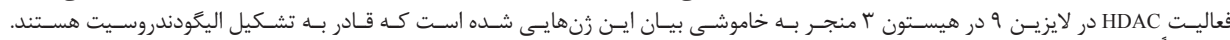

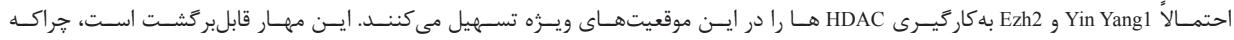

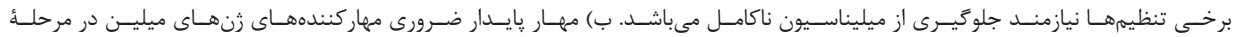

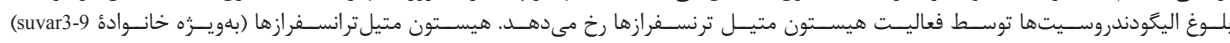

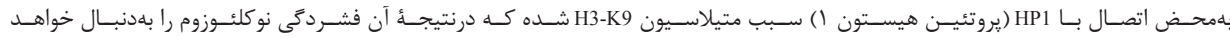

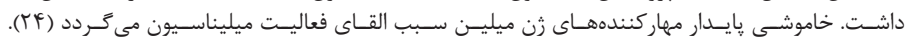

\footnotetext{
${ }^{51}$ Enhancer of zeste homolog 2

${ }^{52}$ Polycomb-group proteins
}

\footnotetext{
${ }^{53}$ Oligodendrocyte progenitor cells

${ }^{54}$ Polycomb repressive complex
} 
متعاقب آن سطوح بالاى سيتروليناسيون، در استخراج ميلين از

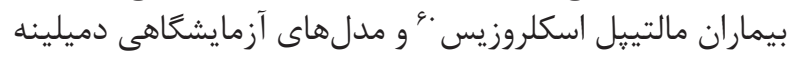

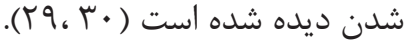

$$
\text { نتيجه }
$$

شبكةٔ تنظيمى خودنوزايى و تمايز سلولهاى بنيادى تركيبى

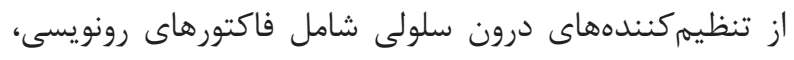

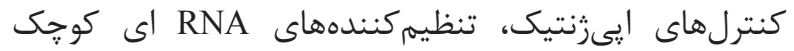

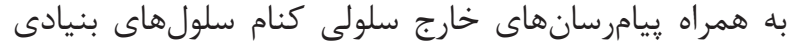

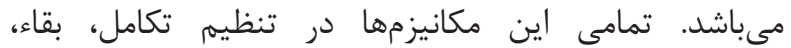

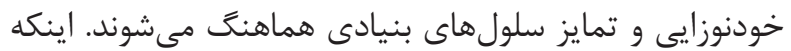

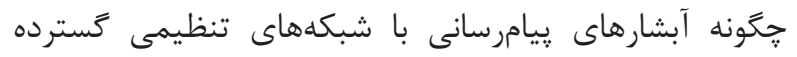

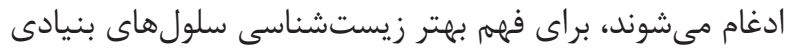

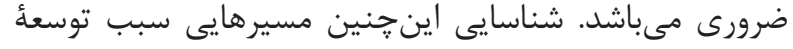

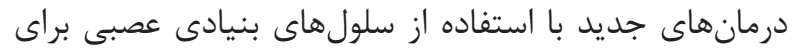

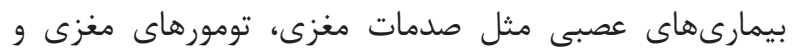

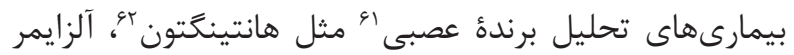

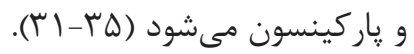

از طرفى ديخر بلوغ عملكردى اليخودندروسيتها درنتيجأ بئه

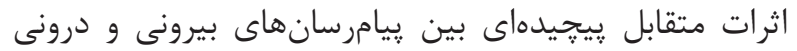

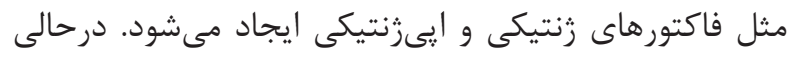

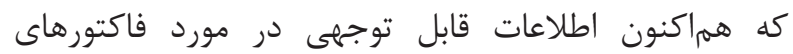
رونويسى اليكودندروزنيكى، زنهائ تمائ تمايز اليكودندروسيتها

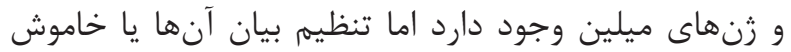

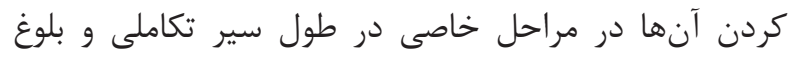

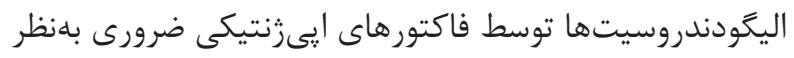

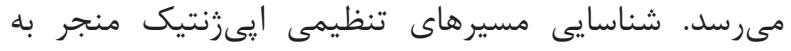

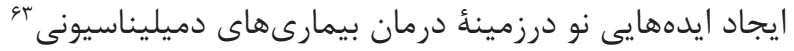

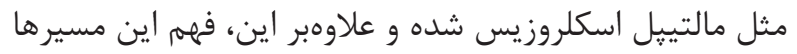

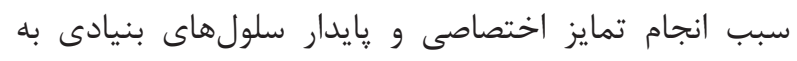

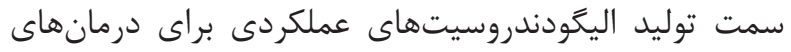

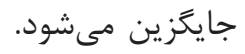

1. Yu J. Chapter 1: The stem cell. Kirschstein R, Skirboll LR. Stem cells: Scientific progress and future research directions. $1^{\text {st }}$ ed. National Institutes of Health. 2001; $1-4$.

2. Tsonis PA. Bridging knowledge gaps on the long road to regeneration: classical models meet stem cell manipulation and bioengineering. $\mathrm{J}$ Mol Intervent. 2007; 7: 249-50.

3. Shi Y, Sun G, Zhao C, Stewart R. Neural stem cell self-renewal. Crit Rev Oncol Hematol. 2008; 65: 43-53.

\footnotetext{
${ }^{55}$ Lysine specific demethylase 1

${ }^{56}$ Jumanji domain

${ }^{57}$ Protein arginine methyltransferase 1

${ }^{58}$ Coactivator-associated arginine methyltransferase 1

${ }^{59}$ Protein-arginine deiminase 2
}

نشان داد كه فرايند متيلاسيون هيستون ديناميك است. همانند

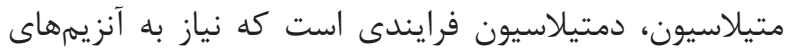

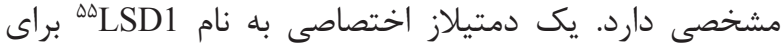

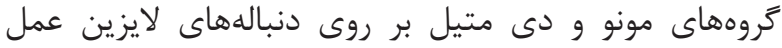

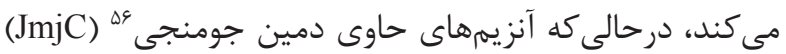

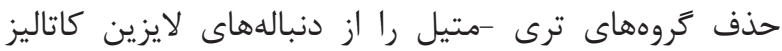

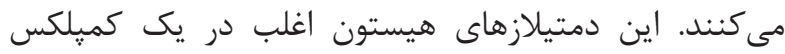

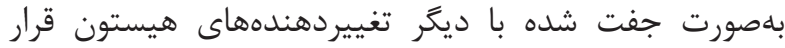

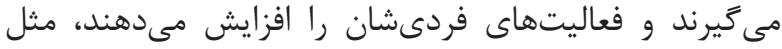

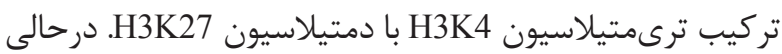

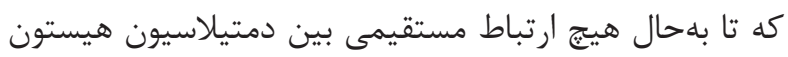

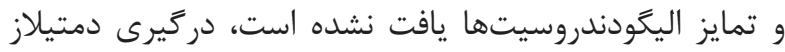

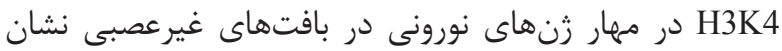

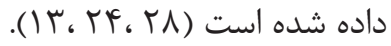

با وجود مطالعات كم، متيلاسيون دنبالههاى آرزنين حالت ديخرى

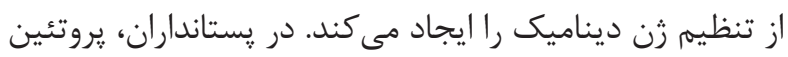

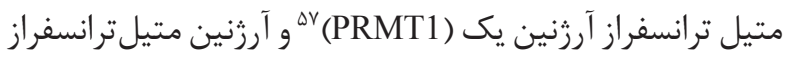

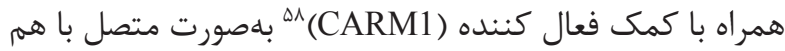

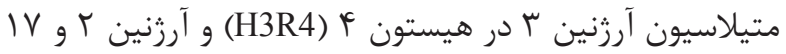

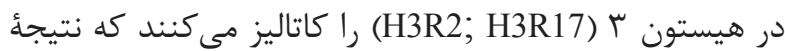

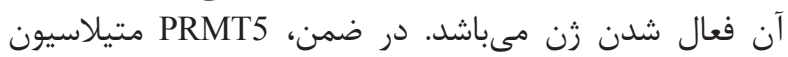

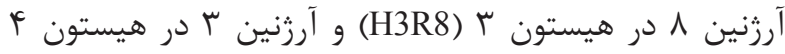

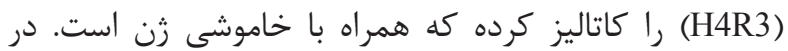

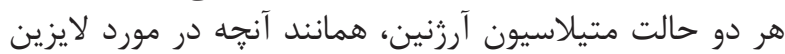

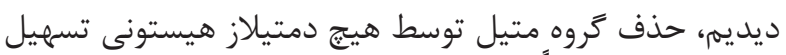

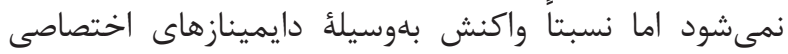

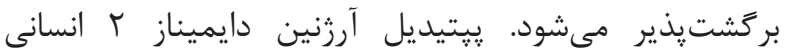

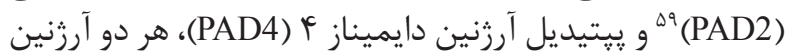

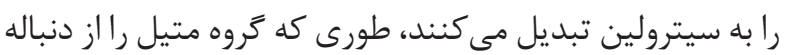

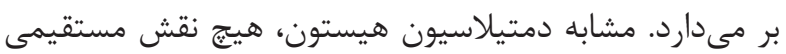

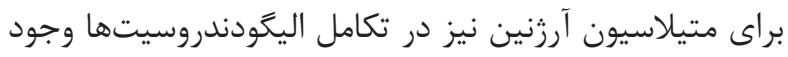

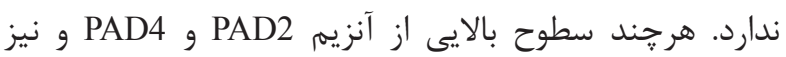

$$
\text { منابع }
$$

4. Gage FH, Kempermann G, Palmer TD, Peterson DA, Ray J. Multipotent progenitor cells in the adult dentate gyrus. J Neurobiol. 1998; 36: 249-66.

5. Alvarez-Buylla A, Temple S. Stem cells in the developing and adult nervous system. J Neurobiol. 1998; 36: 105-10.

6. Shi Y, Chichung LD, Taupin P, Nakashima K, Ray J, $\mathrm{Yu}$ RT, et al. Expression and function of orphan nuclear receptor TLX in adult neural stem cells. Nature. 2004; 427: 78-83.

\footnotetext{
${ }^{60}$ Multiple sclerosis

${ }^{61}$ Neurodegeneration

${ }^{62}$ Huntington

${ }^{63}$ Demyelination
} 
7. Kishi Y, Takahashi J, Koyanagi M, Morizane A, Okamoto Y, Horiguchi S, et al. Estrogen promotes differentiation and survival of dopaminergic neurons derived from human neural stem cells. J Neurosci Res. 2005; 79: 279-86.

8. Hermanson O, Jepsen K, Rosenfeld MG. N-CoR controls differentiation of neural stem cells into astrocytes. Nature. 2002; 419: 934-9.

9. Bylund M, Andersson E, Novitch BG, Muhr J. Vertebrate neurogenesis is counteracted by Sox 1-3 activity. Nat Neurosci. 2003; 11: 1162-8.

10. Ohtsuka T, Sakamoto M, Guillemot F, Kageyama R. Roles of the basic helix-loop-helix genes Hes1 and Hes5 in expansion of neural stem cells of the developing brain. J Biol Chem. 2001; 276: 30467-74.

11. Temple S. Stem cell plasticity-building the brain of our dreams. Nat Rev Neurosci. 2001; 2: 513-520.

12. Ballas N, Grunseich C, Lu DD, Speh JC, Mandel G. REST and its corepressors mediate plasticity of neuronal gene chromatin throughout neurogenesis. J Cell. 2005; 121: 645-57.

13. Kouzarides T. Chromatin modifications and their function. J Cell. 2007; 128: 693-705.

14. Egger G, Liang G, Aparicio A, Jones PA. Epigenetics in human disease and prospects for epigenetic therapy. Nature. 2004; 429: 457-63.

15. Martinowich K, Hattori D, Wu H, Fouse S, He F, Hu $\mathrm{Y}$, et al. DNA methylation-related chromatin remodeling in activity dependent BDNF gene regulation. Science. 2003; 302(5646): 890-3.

16. Mattick JS, Makunin IV. Small regulatory RNAs in mammals. Hum Mol Genet. 2005; 14: 121-32.

17. Smirnova L, Gräfe A, Seiler A, Schumacher S, Nitsch R, Wulczyn FG. Regulation of miRNA expression during neural cell specification. Eur J Neurosci. 2005; 21: 1469-77.

18. Visvanathan J, Lee S, Lee B, Lee JW, Lee SK. The microRNA miR-124 antagonizes the anti-neural REST/ SCP1 pathway during embryonic CNS development. Genes. 2007; 21: 744-9.

19. Lie DC, Colamarino SA, Song HJ, Désiré L, Mira $\mathrm{H}$, Consiglio A, et al. Wnt signalling regulates adult hippocampal neurogenesis. Nature. 2005; 437: 13705.
20. Lasky JL, Wu H. Notch signaling, brain development, and human disease. Pediatr Res. 2005; 57: 104-9.

21. Doetsch F, Petreanu L, Caille I, Garcia-Verdugo JM, Alvarez-Buylla A. EGF converts transit amplifying neurogenic precursors in the adult brain into multipotent stem cells. Neuron. 2002; 36: 1021-34.

22. Mark M, Ghyselinck NB, Chambon P. Function of retinoid nuclear receptors: lessons from genetic and pharmacological dissections of the retinoic acid signaling pathway during mouse embryogenesis. Annu Rev Pharmacol Toxicol. 2006; 46: 451-80.

23. Marlétaz F, Holland LZ, Laudet V, Schubert M. Retinoic acid signaling and the evolution of chordates. Int J Biol Sci. 2006; 2: 38-47.

24. Copray S, Huynh JL, Sher F, Casaccia-Bonnefil $\mathrm{P}$, Boddeke E. Epigenetic mechanisms facilitating oligodendrocyte development, maturation and aging. J Glia. 2009; 57: 1579-87.

25. Shen S, Sandoval J, Swiss VA, Li J, Dupree J, Franklin RJ, et al. Age-dependent epigenetic control of differentiation inhibitors is critical for remyelination efficiency. Nat Neurosci. 2008; 11: 1024-34.

26. Tang BL, Chua CE. SIRT2, tubulin deacetylation, and oligodendroglia differentiation. Cell Motil Cytoskeleton. 2008; 65: 179-82.

27. Chopra VS, Mishra RK. To SIR with Polycomb: linking silencing mechanisms. Bioessays. 2005; 27: 119-21.

28. Benevolenskaya EV. Histone H3K4 demethylases are essential in development and differentiation. Biochem Cell Biol. 2007; 85: 435-43.

29. Paik WK, Paik DC, Kim S. Historical review: the field of protein methylation. Trends Biochem Sci. 2007; 32: $146-52$.

30. Wood DD, Ackerley CA, Brand Bv, Zhang L, Raijmakers R, Mastronardi FG, et al. Myelin localization of peptidylarginine deiminases 2 and 4: comparison of PAD2 and PAD4 activities. Lab Invest. 2008; 88: 35464.

31. Bagherpoor AJ, Bahrami AR, Matin MM, MahdaviShahri N, Edalatmanesh MA. Investigating the effects of vitreous humour (crude extract) on growth and differentiation of rat mesenchymal stem cells (rMSCs) and human NTERA2 cells. Tsitol Genet. 2010; 44(6): $15-21$. 
32. Edalatmanesh MA, Bahrami AR, Hosseini E, Hosseini M, Khatamsaz S. Bone marrow derived mesenchymal stem cell transplantation in cerebellar degeneration: a behavioral study. Behav Brain Res. 2011; 225(1): 63-70.

33. Edalatmanesh MA, Bahrami AR, Hosseini E, Hosseini M, Khatamsaz S. Neuroprotective effects of mesenchymal stem cell transplantation in animal model of cerebellar degeneration. Neurol Res. 2011; 33(9): 913-20.
34. Edalatmanesh MA, Nikfarjam $H$, Moghadas $M$, Haddad-Mashadrizeh A, Robati R, Hashemzadeh MR. Histopathological and behavioral assessment of toxinproduced cerebellar lesion: a potent model for cell transplantation studies in the cerebellum. J Cell. 2014; 16(3): 325-34.

35. Hosseini M, Moghadas M, Edalatmanesh MA, Hashemzadeh MR. Xenotransplantation of human adipose derived mesenchymal stem cells in a rodent model of Huntington's disease: motor and non-motor outcomes. Neurol Res. 2015; 37(4): 309-19. 